\title{
Weight loss during tuberculosis treatment is an important risk factor for drug-induced hepatotoxicity
}

\author{
Ina Warmelink ${ }^{1 *}$, Nick H. ten Hacken ${ }^{2}$, Tjip S. van der Werf ${ }^{2,3}$ and Richard van Altena ${ }^{1}$ \\ ${ }^{1}$ Tuberculosis Center, University Medical Center Groningen (UMCG), PO Box 30002, 9750 RA Haren, The Netherlands \\ ${ }^{2}$ Department of Pulmonary Diseases and Tuberculosis, University Medical Center Groningen (UMCG), PO Box 30001,9700 \\ RB Groningen, The Netherlands \\ ${ }^{3}$ Department of Internal Medicine/Infectious Diseases, University Medical Center Groningen (UMCG), PO Box 30001, 9700 \\ RB Groningen, The Netherlands
}

(Received 23 April 2010 - Revised 20 July 2010 - Accepted 26 July 2010 - First published online 28 September 2010)

\begin{abstract}
The objective of this study was to determine the association between weight loss and drug-induced hepatotoxicity (DIH). A retrospective observational study of 192 active tuberculosis (TB) patients consecutively admitted in a tertiary referral TB centre in the Netherlands was conducted. The outcome measure for DIH was defined as hepatotoxicity necessitating interruption of anti-TB drugs. Multivariate logistic regression analysis on interruption of anti-TB drugs was performed, with age, sex, nutritional status, TB disease severity, drug resistance, comorbidity including baseline liver function tests, anti-TB drug regimen, co-medication and addictions as independent risk factors. Anti-TB drugs were interrupted in thirty-one patients (16.1\%). The most important risk factor was weight loss of $2 \mathrm{~kg}$ or more within 4 weeks during TB treatment (OR 211, $95 \%$ CI 36.0, 1232). Other independent risk factors were infection with hepatitis C (OR 19.6, 95\% CI 2.4, 164), age over 60 years (OR 18.5, $95 \%$ CI 2.3, 151) and multi-drug-resistant TB (OR 8.2, 95\% CI 1.3, 53.6). This study shows that weight loss during TB treatment was the most important risk factor for DIH necessitating interruption of anti-TB drugs. Causes of weight loss during TB treatment and the association between weight change and hepatotoxicity need further investigation.
\end{abstract}

Key words: Malnutrition: Weight loss: Risk factors: Drug-induced hepatotoxicity: Tuberculosis

Drug-induced hepatotoxicity (DIH) is a well-known complication in the treatment of tuberculosis (TB). This may sometimes require interruption of therapy with antiTB drugs. Incidence of hepatotoxicity during treatment of TB disease varies from 5 to $33 \%$. It depends on the study population, definition of hepatotoxicity, anti-TB drugs used, and the way of monitoring ${ }^{(1)}$. Many factors have been associated with DIH. These include TB morbidity ${ }^{(2-5)}$, co-infections such as HIV and hepatitis B and $\mathrm{C}^{(6-12)}$, malnutrition $^{(4,13)}$, old age ${ }^{(14)}$, female sex ${ }^{(2,4,15)}$, elevated transaminases at baseline ${ }^{(14,16-18)}$, and high alcohol intake ${ }^{(3,6)}$.

Malnutrition, as assessed by a low BMI, has been associated with the occurrence of TB-DIH in two studies ${ }^{(4,13)}$. $\mathrm{BMI}$ at the start of $\mathrm{TB}$ treatment is a frequently used static nutritional risk factor in TB research ${ }^{(19,20)}$. Body weight (BW) change after the start of TB treatment may reflect an improving or a worsening nutritional status during TB treatment. In this study we intended to assess the link between this BW change and drug-induced liver toxicity necessitating interruption of anti-TB drugs.

\section{Methods}

Patients

A retrospective review of patients records, admitted between January 2005 and July 2008 at TB Centre Beatrixoord of University Medical Center Groningen, Netherlands, was conducted. All patients $>14$ years of age diagnosed with active Mycobacterium tuberculosis infection ${ }^{(21)}$ were included. Interrupters were patients who had to stop one or more anti-TB drugs for reasons of hepatotoxicity based on international guidelines ${ }^{(1,22)}$.

Controls (non-interrupters) were all other patients admitted during the same study period. The following data about the cases were collected: age, sex, addictions, time to interruption, nutritional status, morbidity,

Abbreviations: BW, body weight; DIH, drug-induced hepatotoxicity; HBV, hepatitis B virus; HCV, hepatitis C virus; MDR-TB, multi-drug-resistant tuberculosis; TB, tuberculosis.

*Corresponding author: I. Warmelink, fax +3150 5338650, email g.warmelink@cvr.umcg.nl 
medication and drug sensitivity test results. Because this was a retrospective chart review with anonymised reporting, approval by the ethics committee was not required.

\section{Nutritional status}

Nutritional status was defined by BW change. BW gain after the start of anti-TB drugs was classified as a gain $\geq 2 \mathrm{~kg}$ within 4 weeks after the start of anti-TB drugs. Weight loss was defined as a decrease in $\mathrm{BW} \geq 2 \mathrm{~kg}$ within 4 weeks after the start of anti-TB drugs. If either weight gain or loss was $<2 \mathrm{~kg}$, BW was considered as stable. If anti-TB drugs were interrupted after more than 4 weeks of treatment, the BW data of the 4 weeks before interruption were used to assess the nature of BW change.

\section{Medication}

Gradual introduction of anti-TB drugs at the start of treatment was defined as an increasing day dose over time or sequential introduction of the drugs. If anti-TB drugs were administered for at least 2 weeks, medication was classified into three possible anti-TB drugs schedules: (1) isoniazid $(\mathrm{H})$, rifampicin $(\mathrm{R})$, pyrazinamid $(\mathrm{Z})$, ethambutol $(\mathrm{E})$; (2) HRZ; (3) other, including drugs for multi-drug-resistant TB (MDR-TB). Day dose was defined as the highest dose of anti-TB drugs in mg per kg baseline BW that had been administered for at least 2 weeks. If interruption of anti-TB drugs occurred within the first 2 weeks of treatment, the day dose was defined as the highest dose given until interruption.
Co-medication administered to anti-TB treatment was classified into no, low or high risk for $\mathrm{DIH}^{(23)}$.

\section{Tuberculosis morbidity}

Patients were classified based on the severity of TB using WHO criteria $^{(21)}$. Classifications were performed independently by two lung specialists. In case of discordance, cases were reviewed and final classifications were reached by consensus.

\section{Comorbidity}

The effect of comorbidity on hepatotoxicity was assessed by applying the Charlson Comorbidity Index ${ }^{(24,25)}$. Infection due to the hepatitis $\mathrm{B}$ virus (HBV), hepatitis $\mathrm{C}$ virus (HCV) and HIV were noted as autonomous morbidity and not included in the Charlson Comorbidity Index. $\mathrm{HBV}, \mathrm{HCV}$ and HIV status were listed positive if medical files noted presence of HBV surface antigen, HCV antibodies and HIV antibodies, respectively.

\section{Statistical analysis}

SPSS for Windows (version 16.0; SPSS, Inc., Chicago, IL, USA) was used for all statistical analyses. Differences in categorical variables between interrupters and noninterrupters were compared using Pearson's $\chi^{2}$ test, or Fisher's exact test for dichotomous variables. Differences in parametric variables were assessed by Student's unpaired

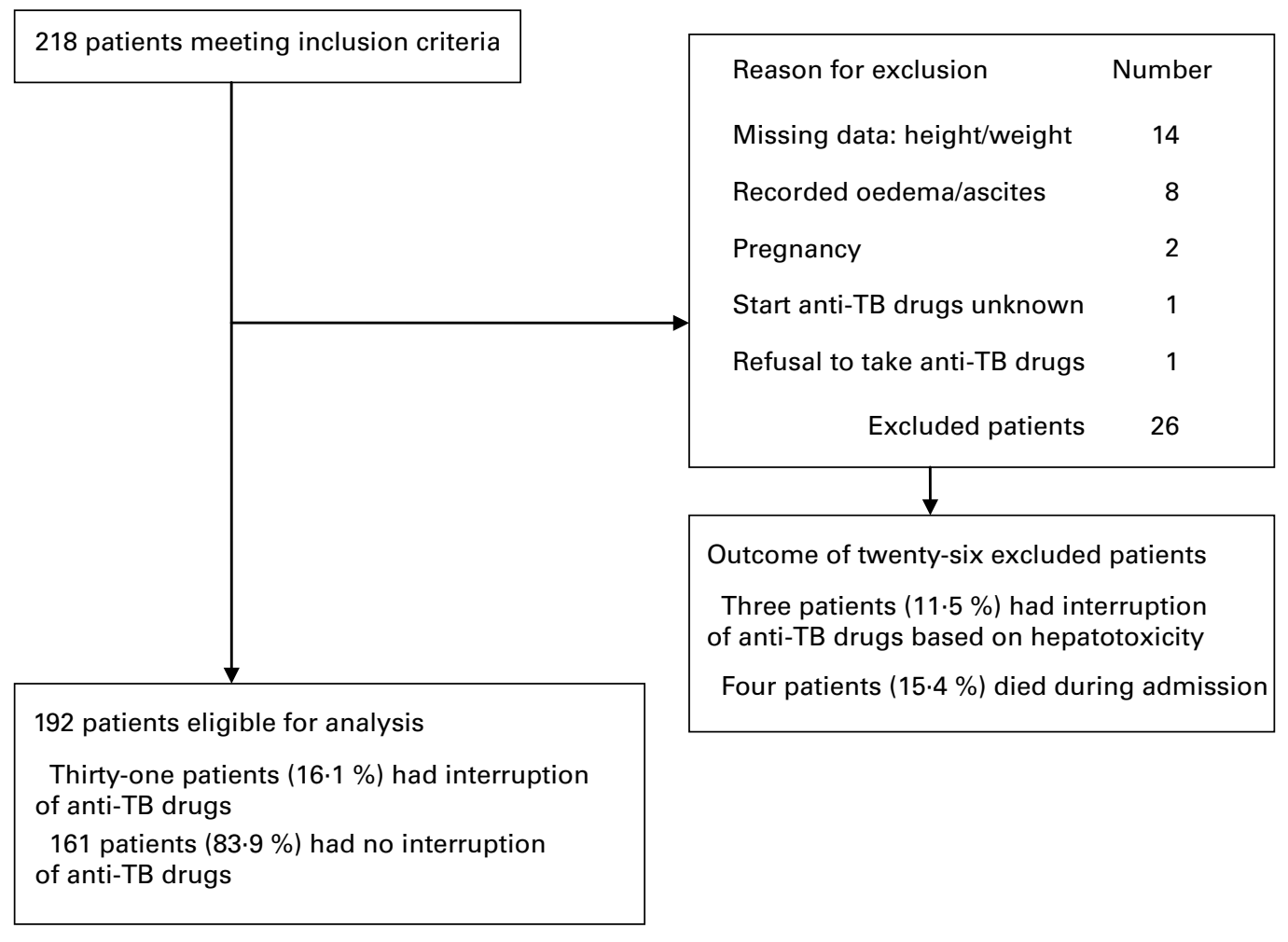

Fig. 1. Flow diagram of study subjects. TB, tuberculosis. 
$t$ test, and in non-parametric variables by the Mann-Whitney $U$ test. All the statistical tests were two sided, and a $P$-value $<0.05$ was considered statistically significant. Variables associated with interruption at a $P$-value $<0 \cdot 1$ in the monovariate analysis and variables that were considered relevant in previous TB hepatotoxicity studies were analysed using multivariate logistical regression. Using the enter method we aimed for a final multivariate model containing the least possible variables that explained the most - the parsimonious model. Cox proportional hazards regression analysis was used to evaluate the simultaneous effect of different variables on time to interruption during $\mathrm{TB}$ treatment. Time to interruption in days was measured from the day of start of anti-TB drugs until the day of interruption. Non-interrupters were censored at $300 \mathrm{~d}$ counted from the start of anti-TB drugs. Kaplan-Meier hazard curves were generated for the primary outcome.

\section{Results}

\section{Study population}

Of the 218 patients admitted during the study period, twenty-six (11.9\%) were excluded from the analysis; the reasons are given in the flow diagram (Fig. 1). Of the remaining 192 patients, thirty-one (16.1\%) developed hepatotoxicity, necessitating interruption of anti-TB drugs.

\section{Demographic data}

There were $148(77 \cdot 1 \%)$ males. The median age of the study population was 38 (range 16-84) years. Patients with interruption of anti-TB drugs were comparable in age, sex, origin, history of alcohol abuse and smoking to non-interrupters. More patients with a history of drug abuse were observed among the non-interrupters (Table 1).

\section{Nutritional status}

A majority of 163 patients (85.3\%) reported BW loss before the start of treatment $v$. twenty-six patients (13.6\%) who reported no BW change, and two patients (1.0\%) who reported BW gain. The reported BW change before the start of TB treatment was not significantly different between interrupters $(-12 \cdot 6 \%$, SD $7 \cdot 1)$ and non-interrupters $(-15 \cdot 0 \%$, SD $11 \cdot 1)$. BMI at the start of treatment did not show any significant difference between interrupters and non-interrupters either. During TB treatment twentyeight patients (14.6\%) lost BW, sixty-four patients $(33.3 \%)$ gained weight and 100 patients (52.1\%) had a stable BW (Table 1).

\section{Medication}

The interrupters and non-interrupters were comparable in all medication characteristics studied, except for the pyrazinamid dose and the number of patients above the recommended upper BW dose of pyrazinamid, which were both lower for the interrupters ${ }^{(26)}$. In the interrupters, BMI was significantly lower and BW doses higher after interruption (Table 2).

Table 1. Patient characteristics†

(Mean values and standard deviations; numbers and percentages)

\begin{tabular}{|c|c|c|c|c|c|}
\hline & \multicolumn{2}{|c|}{$\begin{array}{c}\text { Interrupters } \\
(n 31,16 \cdot 1 \%)\end{array}$} & \multicolumn{2}{|c|}{$\begin{array}{l}\text { Non-interrupters } \\
\text { ( } 1 \text { 161, 83.9\%) }\end{array}$} & \multirow[b]{2}{*}{$P$} \\
\hline & Mean/n & $\mathrm{SD} / \%$ & Mean/n & $\mathrm{SD} / \%$ & \\
\hline Age (years) & 43.7 & $19 \cdot 8$ & $39 \cdot 0$ & $15 \cdot 9$ & 0.317 \\
\hline Female & 8 & $25 \cdot 8$ & 36 & $22 \cdot 4$ & 0.676 \\
\hline Origin & & & & & 0.865 \\
\hline Europe & 13 & 41.9 & 55 & $34 \cdot 2$ & \\
\hline Mediterranean countries $\ddagger$ & 2 & $6 \cdot 5$ & 14 & 8.7 & \\
\hline Sub-Saharan Africa & 11 & 35.5 & 54 & 33.5 & \\
\hline Asia & 3 & $9 \cdot 7$ & 23 & $14 \cdot 3$ & \\
\hline South America & 2 & 6.5 & 15 & $9 \cdot 3$ & \\
\hline Abuse of alcohol ( $n$ 191) & 12 & 38.7 & 55 & 34.4 & 0.683 \\
\hline Abuse of drugs $(n 191) \S$ & 2 & 6.5 & 48 & $30 \cdot 0$ & $0.006^{\star \star}$ \\
\hline History of smoking ( $n$ 173) & 14 & $63 \cdot 6$ & 99 & $65 \cdot 6$ & 1.000 \\
\hline Weight (kg) & $61 \cdot 2$ & $10 \cdot 0$ & $59 \cdot 8$ & $13 \cdot 3$ & 0.368 \\
\hline $\mathrm{BMI}\left(\mathrm{kg} / \mathrm{m}^{2}\right)$ & $20 \cdot 8$ & 3.5 & $20 \cdot 2$ & $4 \cdot 0$ & 0.339 \\
\hline Weight change after start anti-TB drugs & & & & & $<0.001^{* \star *}$ \\
\hline Weight loss $\geq 2 \mathrm{~kg}$ & 22 & 71.0 & 6 & $3 \cdot 7$ & \\
\hline Stable weight & 8 & $25 \cdot 8$ & 92 & $57 \cdot 1$ & \\
\hline Weight gain $\geq 2 \mathrm{~kg}$ & 1 & 3.2 & 63 & 39.1 & \\
\hline
\end{tabular}

TB, tuberculosis.

Values were significantly different: ${ }^{\star \star} P<0.01 ;{ }^{\star * \star} P<0.001$

$\dagger$ The number of analysed/tested patients is 192 , unless otherwise specified.

‡ Mediterranean countries: patients originated from Morocco, and Turkey.

$\S$ Drugs abuse of cocaine, heroine, marijuana. 
Table 2. Medication characteristics†

(Mean values and standard deviations; numbers and percentages)

\begin{tabular}{|c|c|c|c|c|c|}
\hline & \multicolumn{2}{|c|}{$\begin{array}{l}\text { Interrupters } \\
(n 31,16.1 \%)\end{array}$} & \multicolumn{2}{|c|}{$\begin{array}{l}\text { Non-interrupters } \\
(n 161,83.9 \%)\end{array}$} & \multirow[b]{2}{*}{$P$} \\
\hline & Mean/n & $\mathrm{SD} / \%$ & Mean/n & $\mathrm{SD} / \%$ & \\
\hline Gradual introduction of anti-TB drugs ( $n$ 191) & & & & & 0.363 \\
\hline Yes & 5 & $16 \cdot 1$ & 39 & 24.4 & \\
\hline No & 26 & 83.9 & 121 & $75 \cdot 6$ & \\
\hline Anti-TB drugs schedule & & & & & 0.197 \\
\hline HRZE & 21 & $67 \cdot 7$ & 109 & $67 \cdot 7$ & \\
\hline $\mathrm{HRZ}$ & 4 & $12 \cdot 9$ & 8 & $5 \cdot 0$ & \\
\hline Other $\ddagger$ & 6 & 19.4 & 44 & $27 \cdot 3$ & \\
\hline $\mathrm{H}(\mathrm{mg} / \mathrm{kg}, n 175)$ & $5 \cdot 1$ & 0.9 & $5 \cdot 2$ & $1 \cdot 1$ & 0.546 \\
\hline $\mathrm{R}(\mathrm{mg} / \mathrm{kg}, n 172)$ & 9.9 & 1.6 & $10 \cdot 3$ & $2 \cdot 0$ & 0.251 \\
\hline $\mathrm{Z}(\mathrm{mg} / \mathrm{kg}, n$ 170) & $28 \cdot 1$ & $3 \cdot 0$ & $30 \cdot 1$ & 3.7 & $0.003^{\star \star}$ \\
\hline $\mathrm{E}(\mathrm{mg} / \mathrm{kg}, n$ 159) & $22 \cdot 0$ & $4 \cdot 1$ & $20 \cdot 6$ & $3 \cdot 1$ & $0 \cdot 129$ \\
\hline Co-medication & & & & & 0.970 \\
\hline No use or no risk for DIH & 18 & $58 \cdot 1$ & 97 & $60 \cdot 2$ & \\
\hline Low risk for DIH & 10 & $32 \cdot 3$ & 50 & $31 \cdot 1$ & \\
\hline High risk for DIH & 3 & $9 \cdot 7$ & 14 & $8 \cdot 7$ & \\
\hline \multicolumn{6}{|l|}{ Above the upper body weight dose } \\
\hline $\mathrm{H}$ body weight dose $>6 \mathrm{mg} / \mathrm{kg}(n 175)$ & 4 & $16 \cdot 0$ & 31 & $20 \cdot 7$ & 0.788 \\
\hline $\mathrm{R}$ body weight dose $>12 \mathrm{mg} / \mathrm{kg}(n$ 172) & 3 & $12 \cdot 5$ & 25 & $16 \cdot 9$ & 0.770 \\
\hline$Z$ body weight dose $>30 \mathrm{mg} / \mathrm{kg}(n 170)$ & 7 & $25 \cdot 0$ & 79 & $55 \cdot 6$ & $0.004^{\star \star}$ \\
\hline E body weight dose $>20 \mathrm{mg} / \mathrm{kg}(n 159)$ & 14 & $66 \cdot 7$ & 77 & $55 \cdot 8$ & 0.478 \\
\hline \multicolumn{6}{|l|}{ At start treatment } \\
\hline BMl $\left(\mathrm{kg} / \mathrm{m}^{2}, n 31\right) \S$ & $20 \cdot 8$ & 3.5 & & & $0.003^{\star \star}$ \\
\hline \multicolumn{6}{|l|}{ Body weight dose $(\mathrm{mg} / \mathrm{kg}) \S$} \\
\hline $\mathrm{H}(n 25)$ & $5 \cdot 1$ & 0.9 & & & $0.001^{\star \star}$ \\
\hline $\mathrm{R}(n 24)$ & $9 \cdot 9$ & 1.6 & & & $<0.001^{\star \star *}$ \\
\hline$Z(n 28)$ & $28 \cdot 1$ & 3.0 & & & $0.002^{\star \star}$ \\
\hline $\mathrm{E}(n 21)$ & $22 \cdot 0$ & $4 \cdot 1$ & & & $0.006^{\star \star}$ \\
\hline \multicolumn{6}{|l|}{ After interruption } \\
\hline $\mathrm{BMI}\left(\mathrm{kg} / \mathrm{m}^{2}, n 31\right) \S$ & $20 \cdot 0$ & 3.4 & & & $0.003^{\star \star}$ \\
\hline \multicolumn{6}{|l|}{ Body weight dose $(\mathrm{mg} / \mathrm{kg}) \S$} \\
\hline $\mathrm{H}(n 25)$ & $5 \cdot 3$ & 0.8 & & & $0.001^{\star \star}$ \\
\hline $\mathrm{R}(n 24)$ & $10 \cdot 4$ & 1.5 & & & $<0.001^{\star \star *}$ \\
\hline$Z(n 28)$ & $29 \cdot 7$ & 3.4 & & & $0.002^{\star \star}$ \\
\hline $\mathrm{E}(n 21)$ & $23 \cdot 0$ & 3.8 & & & $0.006^{\star \star}$ \\
\hline
\end{tabular}

TB, tuberculosis; H, isoniazid; R, rifampicin; Z, pyrazinamid; E, ethambutol; DIH, drug-induced hepatotoxicity.

Values are significantly different: ${ }^{\star \star} P<0.01 ;{ }^{* \star \star} P<0.001$

$\dagger$ The number of analysed/tested patients is 192, unless otherwise specified.

¥ Other, the anti-TB drugs schedule consists other than the sets HRZE or HZE, with the following drugs: amikacin, capreomycin, clarithromycin, clofazimine, cycloserine, doxycycline, ethambutol, isoniazid, levofloxacin, linozelid, moxifloxacin, prothionamide, pyrazinamide, rifabutin, rifampicin, thioacetazone.

$\S$ The Wilcoxon signed-rank test was used to compare BMI and body weight doses at the start of treatment with those after interruption.

\section{Morbidity and tuberculosis drug susceptibility}

Both the groups were comparable in disease severity, comorbidity, baseline transaminases, TB drug susceptibility of $M$. tuberculosis isolates. Only the proportion of HIVpositive patients was significantly higher among the interrupters than among the non-interrupters (Table 3 ).

\section{Independent risk factors for interruption}

BW loss after the start anti-TB drugs, HCV infection, age $>60$ years and presence of MDR-TB were significant independent risk factors for interruption in a multivariate model. Sex and age were forced into this multivariate model. Age as a continuous variable did not prove linearity in classes of 10 years, therefore we decided to enter the variable of age into two classes ( $>60$ and $\leq 60$ years), based on the results from prior publications ${ }^{(27,28)}$. HBV infection, abnormal baseline aspartate transaminase and drug abuse were not independent risk factors for interruption. These three factors did not contribute to the significance of the other independent risk factors either. For these two reasons they were not added to the final multivariate model. HIV infection was not an independent risk factor for interruption either, nor was it a confounder as it did not alter the main risk factor of interest (weight loss after the start of anti-TB drugs) for more than $10 \%$ of the adjusted OR. For explanatory reasons, HIV infection was kept in the final model. Results of univariate and multivariate analysis for risk factors for interruption in time are shown in Table 4.

\section{Time to interruption}

The median time to interruption was 15 (range 3-270) d. Significant adjusted hazard ratios for time to interruption 
Table 3. Morbidity, comorbidity and tuberculosis (TB) drug susceptibility $\dagger$

(Mean values and standard deviations; numbers and percentage)

\begin{tabular}{|c|c|c|c|c|c|}
\hline & \multicolumn{2}{|c|}{$\begin{array}{l}\text { Interrupters } \\
(\text { n } 31,16 \cdot 1 \%)\end{array}$} & \multicolumn{2}{|c|}{$\begin{array}{l}\text { Non-interrupters } \\
(n 161,83.9 \%)\end{array}$} & \multirow[b]{2}{*}{$P$} \\
\hline & Mean $/ n$ & $\mathrm{SD} / \%$ & Mean/n & $\mathrm{SD} / \%$ & \\
\hline WHO TB classification & & & & & 0.329 \\
\hline Extra pulmonary TB 1 (most severe) & 11 & $35 \cdot 5$ & 37 & $23 \cdot 0$ & \\
\hline Pulmonary TB & 19 & $61 \cdot 3$ & 116 & $72 \cdot 0$ & \\
\hline Extra pulmonary TB 2 (least severe) & 1 & 3.2 & 8 & $5 \cdot 0$ & \\
\hline HBV-pos $\ddagger$ & 1 & $5 \cdot 6$ & 2 & 3.9 & 1.000 \\
\hline HCV-pos $\ddagger$ & 4 & $22 \cdot 2$ & 7 & $13 \cdot 2$ & 0.453 \\
\hline HIV-pos $\ddagger$ & 6 & $25 \cdot 0$ & 9 & $6 \cdot 4$ & $0.011^{*}$ \\
\hline \multicolumn{6}{|l|}{ Charlson Comorbidity Index } \\
\hline Unadjusted for age & 0.48 & 0.81 & 0.32 & 0.68 & 0.218 \\
\hline Adjusted for age & $1 \cdot 1$ & 1.9 & 0.6 & 1.3 & 0.179 \\
\hline Baseline AST (IU//, $n$ 183) & $53 \cdot 3$ & $63 \cdot 3$ & $36 \cdot 4$ & $37 \cdot 6$ & 0.075 \\
\hline Baseline ALT (IU/I, $n$ 183) & $27 \cdot 7$ & $15 \cdot 4$ & $30 \cdot 3$ & $37 \cdot 1$ & 0.507 \\
\hline TB drug susceptibility of Mycobacterium tuberculosis isolates $(n 160) \S$ & & & & & 0.143 \\
\hline Normal susceptibility & 20 & $76 \cdot 9$ & 121 & $90 \cdot 3$ & \\
\hline Mono-drug resistance & 1 & $3 \cdot 8$ & 3 & $2 \cdot 2$ & \\
\hline Multi-drug resistance & 5 & $19 \cdot 2$ & 10 & 7.5 & \\
\hline
\end{tabular}

$\mathrm{HBV}$, hepatitis B virus; pos, positive; HCV, hepatitis C virus; AST, aspartate transaminase; ALT, alanine transaminases.

${ }^{*} P<0.05$.

$\dagger$ The number of analysed/tested patients is 192, unless otherwise specified.

¥ Untested patients with: HBV status $n 123$; HCV status $n 121$; HIV status: $n 28$

$\S$ Untested patients with TB drug susceptibility of strains ( $n 32)$.

were age $>60$ years, BW loss, and HIV- and HCV-infections, and are presented in Table 4. For a patient at the start of TB treatment, the cumulative hazard of interrupting anti-TB drugs within $60 \mathrm{~d}$ was 0.034 (Fig. 2(a)). The cumulative hazard for patients interrupting anti-TB drugs between 60 and $270 \mathrm{~d}$ after the start of TB treatment was $0.058-0.034=0.024$. The adjusted hazard ratio for HIVpositivity was $4 \cdot 2$ (95\% CI 1.40, 12.9) (Table 4, Fig. 2(b)).

Interrupters who lost BW discontinued their anti-TB drugs predominantly in the beginning of treatment: $67 \%$ of those loosing BW interrupted anti-TB drugs within the first $15 \mathrm{~d}$ of treatment, $v$. 33\% after $15 \mathrm{~d} \quad(P=0.046$, Table 5, Fig. 3(a)). In contrast, all interrupters who were HCV-positive discontinued their anti-TB drugs after $30 \mathrm{~d}$ $(P=0.023$; Table 5, Fig. 3(b)). All the interrupters who were MDR-TB patients had to discontinue their anti-TB drugs after $30 \mathrm{~d}$ of TB treatment too $(P=0 \cdot 009$; Table 5$)$.

\section{Discussion}

This retrospective study demonstrated that $\mathrm{TB}$ treatment had to be interrupted due to DIH in $16.1 \%$ of the admitted $\mathrm{TB}$ patients. Weight loss after the start of anti-TB drugs, HCV infection, age $>60$ years and MDR-TB were independent and significant risk factors for interruption. The median time to interruption was 15 (range 3-270) d, and $73 \%$ of the interrupters had to discontinue anti-TB drugs within the first $60 \mathrm{~d}$ of TB treatment.

This is the first report to show that weight loss of $2 \mathrm{~kg}$ or more, developed within 4 weeks during TB treatment, appears to be a highly significant independent risk factor for TB-DIH. Other nutritional factors such as self-reported weight loss before treatment and BMI at the start were not associated with interruption.

In most patients $(85.4 \%)$ in this study BW stabilized or increased during treatment, whereas a small proportion (14.6\%) demonstrated weight loss. Not the BMI at the start of treatment, but the ability to adequate food intake seems to be important during treatment. To our knowledge, research on factors associated with weight loss during TB treatment has not been performed yet. We suggest that side effects of anti-TB drugs, such as gastrointestinal symptoms, which are relatively common in the first few weeks of $\mathrm{TB}$ treatment ${ }^{(29)}$ may result in inadequate food intake ${ }^{(30)}$ and might cause weight loss if gastrointestinal symptoms persist or worsen. Indeed gastrointestinal symptoms have been identified as risk factors for predominantly early interruptions ${ }^{(31)}$, which is in line with weight loss-associated early interruptions in this study (Fig. 3(a), Table 5).

AIDS as a comorbidity might add to weight loss during TB treatment. In this study the BMI at the start of TB treatment was not different between HIV-positive patients and non-HIV positive patients. However, self-reported weight loss noted as the percentage of the normal BW before disease was significantly higher in HIV-positive patients $(21.2 \%)$ than in the non-HIV-positive patients (14.0\%). This weight loss before TB treatment might have caused associated illness and disability to adequate food intake for sustaining or increasing BW during TB treatment in AIDS patients. 

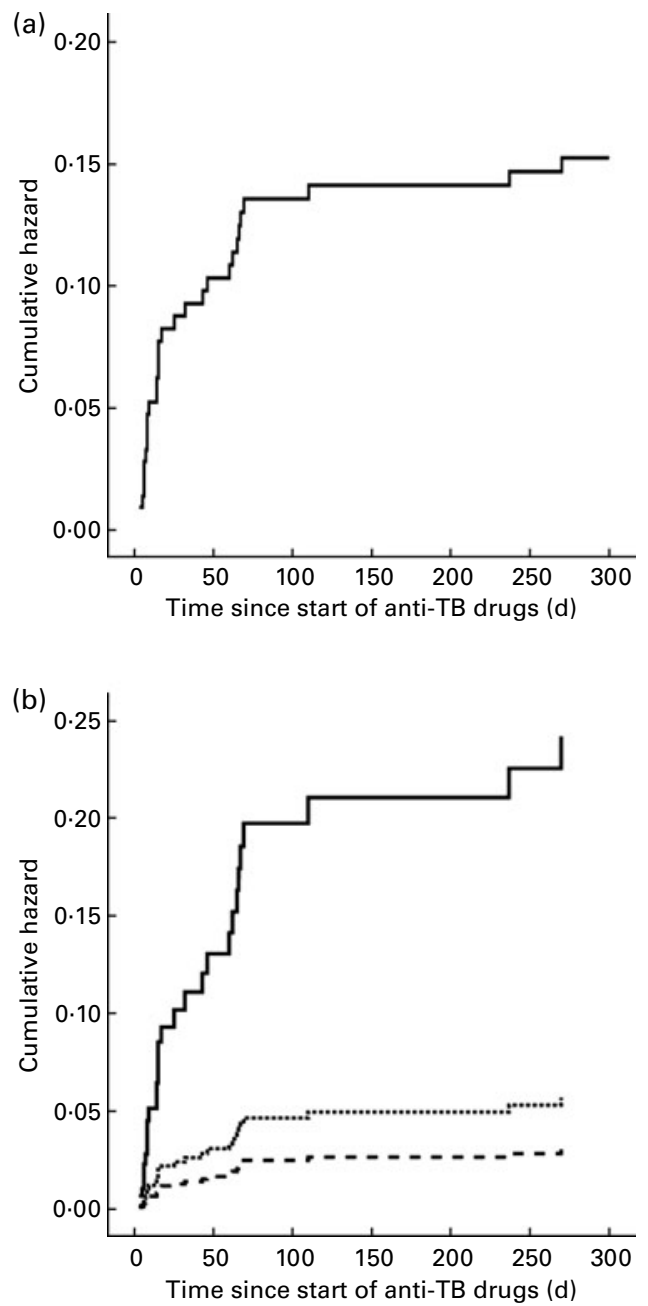

Fig. 2. (a) Cox proportional hazard function of a patient at mean of covariates. (b) Cox proportional hazard function for the HIV status. TB, tuberculosis. ............, No HIV; — , HIV; - . - - -, not tested for HIV.

An adequate intake of nutrients is important for the integrity of liver metabolism and detoxicification of $\mathrm{TB}$ drugs, as the cytochrome P-450 enzyme system is affected by nutrient intake and fasting ${ }^{(32)}$.

Although BW doses of anti-TB drugs were higher after interruption due to weight loss compared to the start of TB treatment (Table 2), we do not consider these higher doses relevant for the development of DIH. There was no difference between interrupters and non-interrupters with regard to BW doses above the recommended upper $\mathrm{BW}$ dose of isoniazid and rifampicin ${ }^{(26)}$. Moreover, a significantly smaller part of interrupters received BW doses of pyrazinamid above the recommended upper BW dose than non-interrupters.

Interrupters who were HCV-positive patients had to interrupt their treatment after $30 \mathrm{~d}$ of treatment, in contrast to those with BW loss who had to interrupt early. This may be caused by a delayed inflammatory immune response against HCV occurring only after several weeks of TB treatment, resulting in hepatic cell damage. At the start of TB treatment the inflammatory response against $\mathrm{HCV}$-infected 

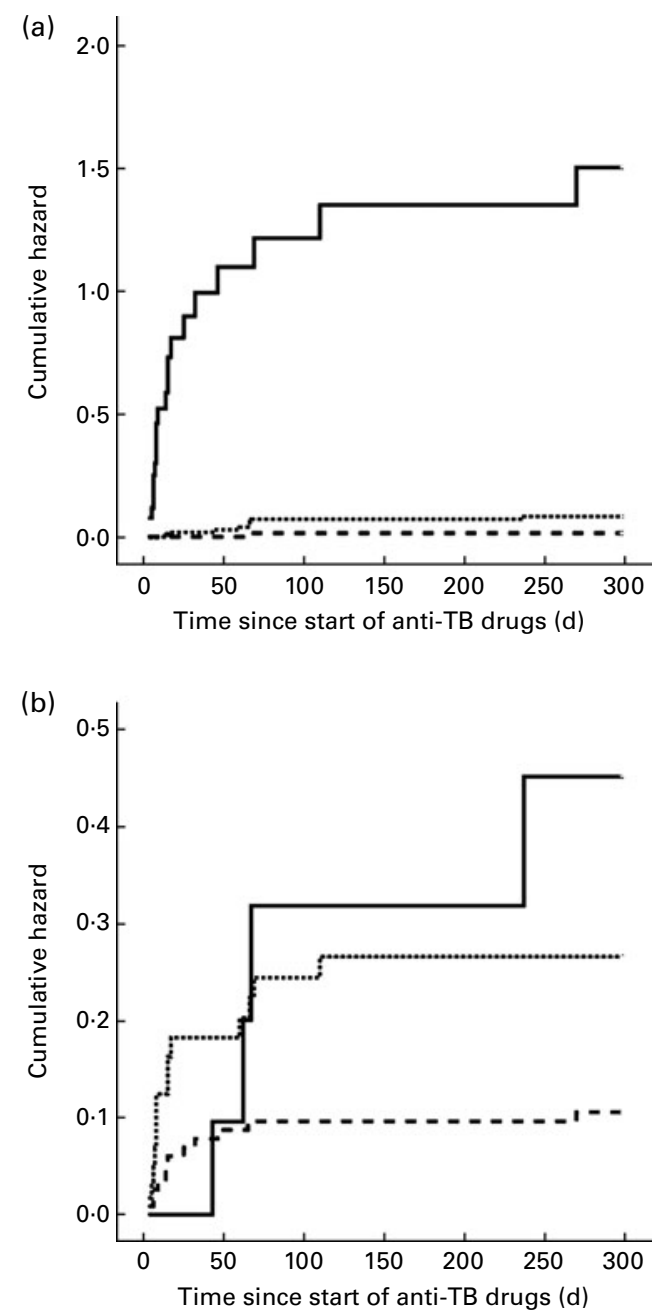

Fig. 3. Kaplan-Meier curve of the hazard for interruption of (a) weight change after start TB treatment and (b) hepatitis $C$ status. TB, tuberculosis; HCV, hepatitis C virus. (a) —, Weight loss; ............, stable weight; - . - . ., weight gain. (b) ............, No HCV; _- HCV; - . - . - not tested for HCV.

liver cells is probably suppressed as a result of untreated TB and associated malnourishment. Shortly after the introduction of successful treatment the inflammatory immune response may restore and target the $\mathrm{HCV}$-infected liver cells. An immune reactivation to HCV during TB treatment with interruption of anti-TB drugs as a result has not been described before and needs further investigation.

Age above 60 years was an independent risk factor for DIH in our model; this has been reported earlier ${ }^{(14)}$. Increased susceptibility for hepatotoxicity with higher age could be partly due to physiological changes. Intravascular, organ, muscle and distribution volumes are usually smaller in the elderly ${ }^{(33)}$, which might result in depressed hepatic drug metabolism and elimination, particularly of drugs metabolised by the cytochrome enzyme system ${ }^{(34,35)}$. Another mechanism may be that elderly people have a reduced food intake ${ }^{(36)}$, causing lower availability of nutrients for liver detoxification of anti-TB drugs. 
MDR-TB as an independent risk factor for TB-DIH has not been reported earlier. MDR-TB treatment lasts longer (typically 18-24 months) and requires drugs which are more toxic than standard treatment drugs for TB. Toxicity developed relatively late (Table 5), and this might reflect immune enhancement as discussed above.

Interruption of anti-TB drugs because of hepatotoxicity typically occurred within the first 2 months of treatment. This is in accordance with other TB-DIH studies ${ }^{(4,5,14,37)}$. The cumulative hazard for interruption was highest during the first $60 \mathrm{~d}$ of treatment (Fig. 2(a)). Concerning the identified factors for interruption, $66.7 \%$ of the weight-losing interrupters had to interrupt anti-TB drugs within the first $15 \mathrm{~d}$ of treatment $v .33 \cdot 3 \%$ after $15 \mathrm{~d}$ of treatment $(P=0.046$; Table 5; Fig. 3(a)). In contrast, all the HCV-infected and all MDR-TB interrupters had to stop anti-TB drugs after $30 \mathrm{~d}$ of treatment (Fig. 3(b), Table 5). To our knowledge this is the first study identifying risk factors for TB-DIH related with time to interruption.

In contrast to other studies, neither $\mathrm{HIV}^{(11,12)}$ nor HBV co-infection ${ }^{(8,10)}$ were identified as independent risk factors, but in the studied population only three patients ( $1 \cdot 2 \%)$ had HBV. Although HIV infection was not identified as a risk factor, a significant hazard ratio of $4 \cdot 2$ for interruption of HIV-positivity was found. This hazard ratio implies that the simultaneous effects of risk factors of the HIVpositive patients together exerted a hazard over time to cause interruption (Fig. 2(b)). Because in five of the six HIV-positive interrupters weight loss was identified, we speculate that weight loss is an important risk factor for HIV-positive patients in TB-DIH.

In contrast to other studies ${ }^{(2-5)}$, severity of $\mathrm{TB}$ disease was not associated with hepatotoxicity. Of the 192 patients, most $(70 \cdot 3 \%)$ were classified in the pulmonary TB class. This large class of pulmonary TB probably included patients with a very broad range of clinical disease severity, decreasing the possible association between the disease severity and interruption.

The strength of the study is the heterogeneous study population with many risk factors for hepatotoxicity. The limitations of the study are the retrospective design and the primary outcome measure of interruption which is not based on strictly defined criteria.

Interruption of treatment of $\mathrm{TB}$ prolongs treatment, increasing the social and economic burden for the patient and the community. This study shows that weight loss was the most important risk factor. Prospective studies are urgently needed to assess the cause-and-effect relationship between weight loss and an evolving DIH during TB treatment.

In conclusion, weight loss of $2 \mathrm{~kg}$ or more during $\mathrm{TB}$ treatment was a significant independent risk factor for interruption of anti-TB drugs. For interruption, which occurs predominantly within the first $60 \mathrm{~d}$ of TB treatment, $\mathrm{HCV}$ infection, age $>60$ years and MDR-TB were also identified as significant risk factors.

\section{Acknowledgements}

The authors thank Judith Vonk for statistical advice. Alie de Boer and Natascha van Weerlee are thanked for their administrative support. I. W. was sponsored by a grant from the Netherlands Beatrixoord Foundation (grant no. WO 210.093). There is no conflict of interest to report. I. W. was the principal investigator and in charge of data collection, analysis and writing the manuscript. N. H. t. H., T. S. v. d. W. and R. A. contributed to the design of the study. R. v. A. helped in the data collection. N. H. t. H. contributed to the data analysis and writing of the manuscript, and provided advice and consultation. R. v. A. and T. S. v. d. W. were responsible for classification of the TB disease severity. Final manuscript review and approval was done by I. W., N. H. t. H., T. S. v. d. W. and R. v. A.

\section{References}

1. Saukkonen JJ, Cohn DL, Jasmer RM, et al. (2006) An official ATS statement: hepatotoxicity of antituberculosis therapy. Am J Respir Crit Care Med 174, 935-952.

2. Dossing M, Wilcke JT, Askgaard DS, et al. (1996) Liver injury during antituberculosis treatment: an 11-year study. Tuber Lung Dis 77, 335-340.

3. Pande JN, Singh SP, Khilnani GC, et al. (1996) Risk factors for hepatotoxicity from antituberculosis drugs: a case-control study. Thorax 51, 132-136.

4. Shakya R, Rao BS \& Shrestha B (2004) Incidence of hepatotoxicity due to antitubercular medicines and assessment of risk factors. Ann Pharmacother 38, 1074-1079.

5. Sharma SK, Balamurugan A, Saha PK, et al. (2002) Evaluation of clinical and immunogenetic risk factors for the development of hepatotoxicity during antituberculosis treatment. Am J Respir Crit Care Med 166, 916-919.

6. Fernandez-Villar A, Sopena B, Garcia J, et al. (2007) Hepatitis $\mathrm{C}$ virus RNA in serum as a risk factor for isoniazid hepatotoxicity. Infection 35, 295-297.

7. Lanternier F, Dalban C, Perez L, et al. (2007) Tolerability of anti-tuberculosis treatment and HIV serostatus. Int J Tuberc Lung Dis 11, 1203-1209.

8. Lee BH, Koh WJ, Choi MS, et al. (2005) Inactive hepatitis B surface antigen carrier state and hepatotoxicity during antituberculosis chemotherapy. Chest 127, 1304-1311.

9. Marzuki OA, Fauzi AR, Ayoub S, et al. (2008) Prevalence and risk factors of anti-tuberculosis drug-induced hepatitis in Malaysia. Singapore Med J 49, 688-693.

10. Patel PA \& Voigt MD (2002) Prevalence and interaction of hepatitis B and latent tuberculosis in Vietnamese immigrants to the United States. Am J Gastroenterol 97, 1198-1203.

11. Ungo JR, Jones D, Ashkin D, et al. (1998) Antituberculosis drug-induced hepatotoxicity. The role of hepatitis $\mathrm{C}$ virus and the human immunodeficiency virus. Am J Respir Crit Care Med 157 (6 Pt 1), 1871-1876.

12. Yimer G, Aderaye G, Amogne W, et al. (2008) Anti-tuberculosis therapy-induced hepatotoxicity among Ethiopian HIVpositive and negative patients. PLoS One 3, e1809.

13. Singh J, Arora A, Garg PK, et al. (1995) Antituberculosis treatment-induced hepatotoxicity: role of predictive factors. Postgrad Med J 71, 359-362.

14. Teleman MD, Chee CB, Earnest A, et al. (2002) Hepatotoxicity of tuberculosis chemotherapy under general programme conditions in Singapore. Int J Tuberc Lung Dis 6, 699-705. 
15. Lee AM, Mennone JZ, Jones RC, et al. (2002) Risk factors for hepatotoxicity associated with rifampin and pyrazinamide for the treatment of latent tuberculosis infection: experience from three public health tuberculosis clinics. Int $J$ Tuberc Lung Dis 6, 995-1000.

16. Fernandez-Villar A, Sopena B, Fernandez-Villar J, et al. (2004) The influence of risk factors on the severity of antituberculosis drug-induced hepatotoxicity. Int $J$ Tuberc Lung Dis 8, 1499-1505.

17. Lobato MN, Reves RR, Jasmer RM, et al. (2005) Adverse events and treatment completion for latent tuberculosis in jail inmates and homeless persons. Chest 127, 1296-1303.

18. Sun HY, Chen YJ, Gau CS, et al. (2009) A prospective study of hepatitis during antituberculous treatment in Taiwanese patients and a review of the literature. J Formos Med Assoc 108, 102-111.

19. Johnston JC, Shahidi NC, Sadatsafavi M, et al. (2009) Treatment outcomes of multidrug-resistant tuberculosis: a systematic review and meta-analysis. PLoS One 4, e6914.

20. Hanrahan CF, Golub JE, Mohapi L, et al. (2010) Body mass index and risk of tuberculosis and death. AIDS 24, 1501-1508.

21. Maher D, Chaulet P, Spinaci P, et al. (1997) Treatment of Tuberculosis: Guidelines for National Programmes. Geneva: World Health Organization.

22. Chemotherapy and management of tuberculosis in the United Kingdom: recommendations 1998. Joint Tuberculosis Committee of the British Thoracic Society (1998) Thorax 53, $536-548$

23. van Hest R, Baars H, Kik S, et al. (2004) Hepatotoxicity of rifampin-pyrazinamide and isoniazid preventive therapy and tuberculosis treatment. Clin Infect Dis 39, 488-496.

24. Hall WH, Ramachandran R, Narayan S, et al. (2004) An electronic application for rapidly calculating Charlson comorbidity score. BMC Cancer $\mathbf{4}, 94$.

25. de Groot V, Beckerman H, Lankhorst GJ, et al. (2003) How to measure comorbidity. A critical review of available methods. J Clin Epidemiol 56, 221-229.

26. World Health Organization (2010) Treatment of Tuberculosis: Guidelines. Geneva: WHO.
27. Schaberg T, Rebhan K \& Lode H (1996) Risk factors for sideeffects of isoniazid, rifampin and pyrazinamide in patients hospitalized for pulmonary tuberculosis. Eur Respir $J$ 9, 2026-2030.

28. Yee D, Valiquette C, Pelletier M, et al. (2003) Incidence of serious side effects from first-line antituberculosis drugs among patients treated for active tuberculosis. Am J Respir Crit Care Med 167, 1472-1477.

29. Blumberg HM, Burman WJ, Chaisson RE, et al. (2003) American Thoracic Society/Centers for Disease Control and Prevention/Infectious Diseases Society of America: treatment of tuberculosis. Am J Respir Crit Care Med 167, 603-662.

30. Warmelink G, Poels BJ, van Altena R, et al. (2007) Indications for percutaneous endoscopic gastrostomy in complex tuberculosis patients. Int J Tuberc Lung Dis 11, 85-90.

31. Baghaei P, Tabarsi P, Chitsaz E, et al. (2010) Incidence, clinical and epidemiological risk factors, and outcome of drug-induced hepatitis due to antituberculous agents in new tuberculosis cases. Am J Ther 17, 17-22.

32. Guengerich FP (1995) Influence of nutrients and other dietary materials on cytochrome P-450 enzymes. Am J Clin Nutr 61, 651S-658s

33. Schwartz JB (2007) The current state of knowledge on age, sex, and their interactions on clinical pharmacology. Clin Pharmacol Ther 82, 87-96.

34. Cusack BJ (2004) Pharmacokinetics in older persons. Am J Geriatr Pharmacother 2, 274-302.

35. Jorquera F, Culebras JM \& Gonzalez-Gallego J (1996) Influence of nutrition on liver oxidative metabolism. Nutrition 12, 442-447.

36. Alix E, Berrut G, Bore M, et al. (2007) Energy requirements in hospitalized elderly people. J Am Geriatr Soc 55, 1085-1089.

37. Sharifzadeh M, Rasoulinejad M, Valipour F, et al. (2005) Evaluation of patient-related factors associated with causality, preventability, predictability and severity of hepatotoxicity during antituberculosis (correction of antituberclosis) treatment. Pharmacol Res 51, 353-358. 